\title{
Current Status of Dendritic Cell-Based Tumor Vaccination
}

\author{
J. Dannulla T. Cerny ${ }^{b} \quad$ D.K. Ackermann ${ }^{c} \quad$ M. Groettrup ${ }^{a}$ \\ a Laborforschungsabteilung, \\ ${ }^{\mathrm{b}}$ Abteilung für Onkologie, \\ c Abteilung für Urologie, Kantonsspital St. Gallen
}

\section{Key Words}

Dendritic cells · Immunotherapy · Vaccination ·

Tumor-associated antigens

\begin{abstract}
Summary
For several decades, approaches utilizing nonspecific immune stimulants have provided evidence that the immune system, when properly activated, may eradicate cancer cells. However, it was only after the identification of the first human tumor-associated antigen, less than a decade ago, that development of specific vaccination procedures for cancer patients became feasible. Recent insights into the pivotal role of dendritic cells (DCs) for initiation and regulation of immune responses have allowed the design of DC-based tumor vaccination trials. In addition, the development of methods to raise large numbers of DCs from peripheral blood monocytes has paved the way for their clinical application. Tumor-specific vaccination utilizing antigen-loaded autologous DCs, has become practical and applicable to patients and may lead to vigorous antitumor responses. This review outlines recent progress, obstacles still to be overcome, and the future potential of DC-based vaccination.
\end{abstract}

\section{Generating a Potent Antitumor Response}

A prerequisite for establishing a potent and durable antitumor immune response is the simultaneous activation of antigenpresenting cells (APCS) including B cells, macrophages and dendritic cells $D C s, C D 4+$ helper $T$ cells $\left(T_{h}\right.$ cells), cytolytic CD 8+ T cells (CTLS), and antibody-secreting $B$ cells. U pon activation, $T_{h}$ cells secrete cytokines which, in turn, stimulate CTL $s$ and $B$ cells and, furthermore, augment the killing activity of natural killer cells (NK) as well as the phagocytic capacity of macrophages. A ppropriately activated, CTLs are capable of

\author{
Schlüsselwörter \\ Dendritische Zellen · Immuntherapie · Impfung · \\ Tumor-assoziierte Antigene
}

\section{Zusammenfassung}

Seit einigen J ahrzehnten haben Studien zur immunologischen Tumortherapie Hinweise dafür geliefert, dass ein aktiviertes Immunsystem Tumorzellen eliminieren kann. Durch die Identifikation von Tumorantigenen in den vergangenen $10 \mathrm{~J}$ ahren ist es heute möglich, Krebspatienten Antigen-spezifisch gegen Tumoren zu immunisieren. Neue Erkenntnisse über die enorme Bedeutung von dendritischen Zellen (DCs) für die Aktivierung und die Regulation der Immunantwort haben die Entwicklung von klinischen Studien für die Behandlung vieler verschiedener Neoplasien entscheidend geprägt. Methoden sind entwickelt worden, welche die Züchtung von autologen DCs aus Monozyten des peripheren Bluts in großer Anzahl erlauben und den Weg für deren klinische Anwendung ebnen. Impfungen mit Tumorantigen-beladenen DCs sind klinisch praktikabel und haben das Potential, starke zelluläre Immunantworten gegen Tumoren zu erzeugen. Dieser Artikel gibt eine Übersicht über neueste klinische Fortschritte in der Tumorvakzinierung mit DCs und diskutiert, wie bestehende Probleme mit neuen Therapieansätzen bewältigt werden könnten.

directly killing tumor cells. A PCs play a pivotal role in this scenario as they are able to bridge the innate, cellular and humoral arms of the immune system. A PCs ingest parts of tumor cells or antigens and process and display them as peptide epitopes with a length of 9-20 amino acids on the major histocompatibility complex (M HC) class I and class II proteins. $T_{h}$ cells recognize their cognate antigens in the context of M HC class II molecules which are only found on A PCs, whereas CTL s do so in the context of M HC classI which is expressed on all somatic cells, except testis, placenta, and the majority of neurons. E ach T-cell receptor (TCR) on naive $T$ cells binds

Konstanzer Online-Publikations-System (KOPS)

URL: http://nbn-resolving.de/urn:nbn:de:bsz:352-221442

\begin{tabular}{|c|c|c|}
\hline KARGER & (c) 2000 S. K arger G mbH , Freiburg & $\begin{array}{l}\text { Dr. J ens D annull } \\
\text { Laborforschungsabteilung, } \mathrm{H} \text { aus } 09\end{array}$ \\
\hline $\begin{array}{l}\text { Fax }+497614520714 \\
\text { E-mail Information@K arger.de } \\
\text { www.karger.com }\end{array}$ & $\begin{array}{l}\text { A ccessible online at: } \\
\text { www.karger.com/journals/onk }\end{array}$ & $\begin{array}{l}\text { K antonsspital St. G allen } \\
\text { CH -9007 St. G allen (Switzerland) } \\
\text { Tel. +41 } 71 \text { 494-1097, Fax - } 6321 \\
\text { E-mail Ifawissll @msl.kssg.ch }\end{array}$ \\
\hline
\end{tabular}


only to its cognate $\mathrm{MHC}$ /antigen complex, leading to the exquisite specificity typical for cellular immunity. In addition to recognizing foreign antigens, $T$ cells need to receive signals through costimulatory receptors in order to become fully activated (fig. 1). T cells that encounter their cognate antigen without proper costimulation (e.g. on non-A PCs) may be rendered anergic or ignorant, thus precluding an immune response. Costimulation is delivered through CD 28, CD 40L ( $L$, ligand) and $0 \times 40$ on $T$ cells interacting with the surface proteins $B$ 7-1, CD 40, and $0 \times 40 \mathrm{~L}$, respectively, that are present on professional APCs (fig. 1). Ligation of CD 40 and CD 40L induces upregulation of adhesion and costimulatory molecules and the production of IL-12 by DCs, a key cytokine for stimulating CTL responses [1]. Furthermore, interaction between $C D 28$ and $0 \times 40$ and their respective receptors $B 7-1$ and $0 \times 40 \mathrm{~L}$ synergistically activates $T$-cell proliferation, leading to a rapid expansion of antigen-specific $T$ cells. A negative regulator of costimulation, CTLA - 4, is expressed along with CD 28 on $T_{h}$ cells [2]. CTLA - 4 can counteract CD 28-mediated costimulation and, therefore, downregulate $\mathrm{T}$-cell responses by raising the threshold of signal needed for effective T-cell activation or alternatively by termination of ongoing T-cell responses. Strategies that target costimulatory signals have become an area of intense investigation and may enable rational therapeutic approaches for manipulating the immune response.

\section{Dendritic Cells}

D C s represent a unique system of cells [3] that induce, sustain, and regulate immune responses (for an electron microscopic image of a dermal DC see fig. 2). DCs originate in the bone marrow from pluripotent CD 34+ stem cells and migrate to peripheral tissues through the blood. They are distributed in most tissues and, in particular, in tissues that interface with the external environment. $\mathrm{H}$ ere, they perform sentinel function for incoming pathogens. L angerhans cells, the first D C s described, are widely distributed in skin, esophagus, cervix, and buccal epithelia. Interstitial DCs are present in the dermis as well as the interstitium of virtually all tissues, except the brain. Furthermore, veiled DCs may be found in the afferent lymph, and interdigitating DCs reside in the cortical zone of the lymph nodes and in the spleen. The DCs in peripheral tissues are immature but capable of actively taking up antigens by three major pathways: Macropinocytosis allows uptake of soluble extracellular antigens. In addition, phagocytosis or receptormediated endocytosis may be initiated by direct, nonopsonic, interaction between pathogen, apoptotic cells, or effete body cells and DCs. A s depicted in figure 3a, receptor-mediated uptake may occur via DEC-205 (multilectin receptor on DCs and thymic epithelial cells, the human homolog being gp200$M R 6$ ), the mannose receptors, collectins (collagen-like lectins), toll-like receptors (TLR 2,4), and the scavenger receptors. A Iternatively, antibodies or complement can act as bridging molecules between pathogen and Fc-type (FcyR I-II) or complement-type receptors, thus leading to opsonic uptake.

Following uptake of antigens, DCs induce leukocyte recruitment to the site of inflammation through production of chemokines and inflammatory cytokines. Subsequently, D C s undergo

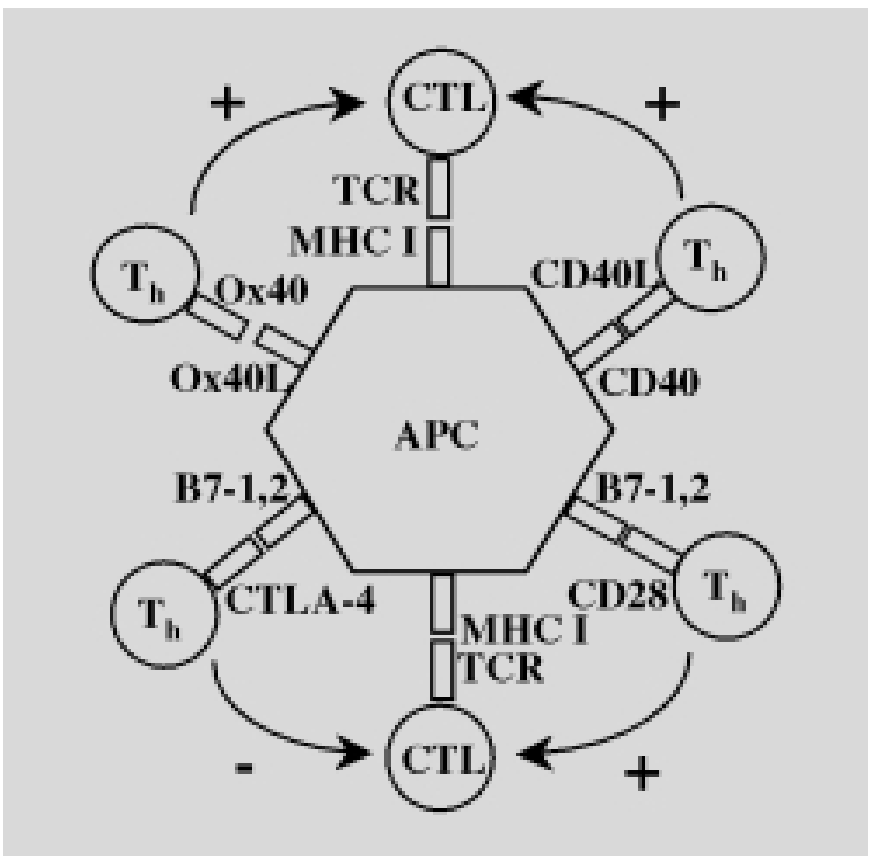

Fig 1 Costimulation of T cells provided by professional A PCs. Ligation of CD 40L, Ox40, and CD 28 expressed on $T_{h}$ cells with CD 40, OX 40L, and $B-7.1$ and $B-7.2$ on professional A PCs leads to rapid expansion of antigenspecific CTL s. CTLA -4 is expressed on $T_{h}$ cells and can attenuate CD 28mediated costimulation. CD = Cluster of differentiation, CTLA -4, T-lymphocyte-associated antigen 4.

a switch in the expression of chemokine receptors which allows them to leave the inflamed tissue and to migrate to draining lymphoid organs, in particular the T-cell areas of lymph nodes. $\mathrm{H}$ ere, they undergo a process of maturation and acquire the ability to attract T cells by expression of M DC (macrophagederived chemokine) and E LC (E BV-induced molecule 1 ligand chemokine) as well as to initiate $\mathrm{T}$-cell responses. $\mathrm{M}$ aturation of DCs is accompanied by a decrease of receptors involved in uptake of antigen and an increase in the expression of $\mathrm{M} \mathrm{HC}$ class I and class II molecules. Furthermore, upregulation of costimulatory molecules and of adhesion molecules (ICA M -1, ICA M-3, and LFA-3) which are essential for antigen-independent binding occurs in mature DCs. The mature stage of DCs ends by apoptotic cell death in the lymph node which is greatly enhanced by immunoinhibitory cytokines such as IL -10. The understanding and consideration of these properties of $D C$ s is imperative for the design of tumor vaccines and will be discussed below.

\section{Generation of DCs for Vaccination Purposes in vitro}

Two standard methods for in vitro generation of human DCs have been described $[4,5]$. The first of which utilizes hematopoietic CD 34+ precursor cells which are harvested from bone marrow, umbilical cord or peripheral blood. These cells are cultured ex vivo in the presence of GM-CSF (granulocytemacrophage colony-stimulating factor) and TNF- $\alpha$ (tumor necrosis factor-alpha), leading to yields of $10^{6}$ D Cs per $500 \mathrm{ml}$ 


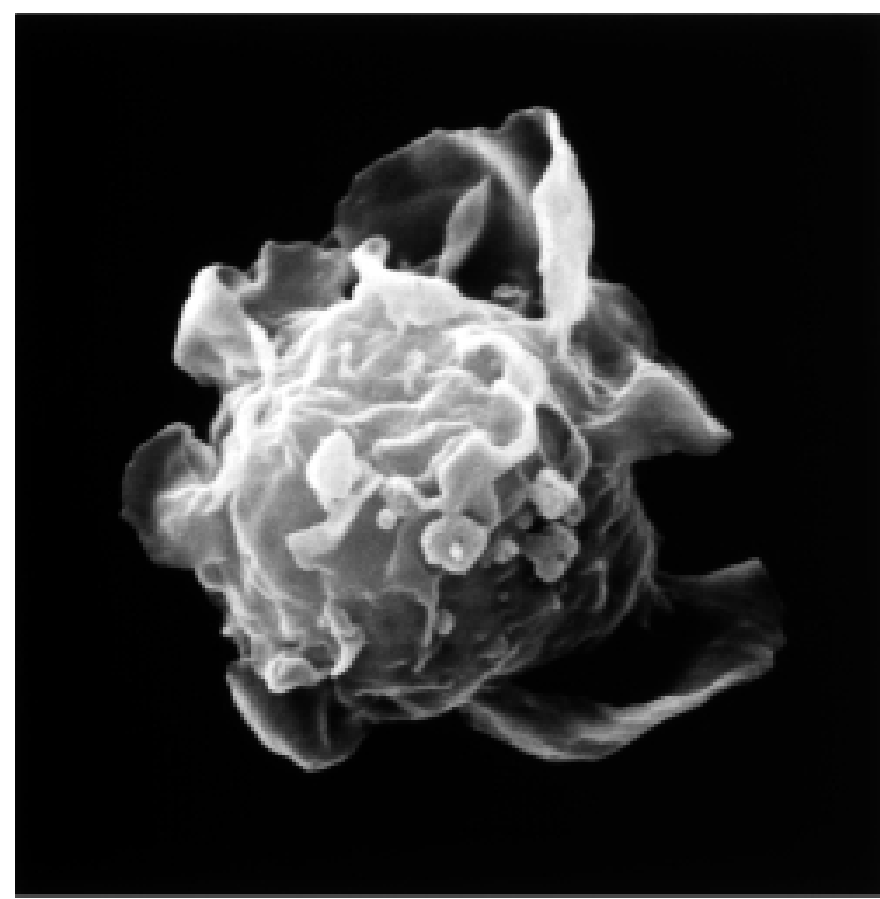

Fig 2. Image of a mature human $D C$. The $D C$ was isolated from the dermis [28], and the image was obtained by scanning electron microscopy. This picture was kindly contributed by Frank Nestle and Luis Filgueira, U niversity H ospital Zürich.

of peripheral blood and about $2 \times 10^{6} \mathrm{DCs}$ per $1 \mathrm{ml}$ of bone marrow. A different and more practical approach utilizes CD 14+ monocytes from peripheral blood cells which differentiate to DCs in the presence of GM-CSF and IL -4 . U sing this method, $10^{6} \mathrm{DCs}$ can be obtained from $10 \mathrm{ml}$ of peripheral blood. The yield of DCs can be further increased up to 5-10fold by pretreatment of donors with recombinant GM-CSF or FIt-3 ligand (c-fms-like tyrosine kinase), a method which is currently under clinical investigation. Following ex vivo generation and loading with tumor antigen, autologous DCs can be reinjected into patients. This autoadoptive transfer can be performed with immature DCs or with DCs that have been matured in vitro by a standard procedure employing prostaglandin E 2, IL -1 $\beta$, IL -6, and TN F - $\alpha$ [6]. I mportantly, methods have been developed to cryopreserve matured DCs which greatly facilitates their clinical application. In sum, ex vivo generation of DCs for vaccination approaches has proved to be practical and safe, and, additionally, allows to circumvent immunosuppressive conditions observed in cancer tissues.

\section{Identification of Tumor-Associated Antigens}

D isappointing results from clinical vaccination trials may give the wrong impression that tumors are not sufficiently distinct from normal tissue to activate the immune system and would, therefore, be nonimmunogenic. However, there is strong evidence that lack of immunogenicity can be due to the tumor's ability to actively evade recognition by the immune system. Several mechanisms by which tumors are capable of blunting an immune response have been demonstrated. These include downregulation of $\mathrm{MHC}$ class I expression and $\beta_{2}-$ microglobulin (and/or loss of transporter associated with antigen presentation (TA P)), overexpression of immunoinhibitory cytokines such as TGF- $\beta_{1}$ and IL-10 and induction of Fasmediated apoptosis of $\mathrm{T}$ cells via expression of Fas ligand (FasL) by a variety of malignancies. However, there is solid evidence that unaltered self-antigens aberrantly expressed in tumors or expressed in a tissue-specific fashion can be recognized by $T$ cells from cancer patients. A ccordingly, autoreactive $\mathrm{T}$ cells, even though they might display low avidity, escape thymic deletion and reach the periphery where they could be involved in antitumor responses - if properly activated. The isolation of the first human tumor-associated antigens (TA A s) recognized by CTL from melanoma patients represents a milestone of contemporary immunotherapy [7]. This seminal work for identification of TAAS is based on the recognition of appropriate target cells (transfected with CDNA libraries prepared from tumor tissue) by autologous tumor-specific CTL clones in vitro.

A Iso, the analysis of serological responses to tumors combined with molecular cloning techniques, known as SEREX (serological analysis of autologous tumor antigens by recombinant expression cloning), is a promising means of identifying novel antigens [8]. It allows an unbiased search for an antibody response and the direct molecular identification of immunogenic tumor proteins based on their reactivity with autologous patient sera. SE REX analyses have led to the identification of a variety of novel antigens whose clinical potential is currently under investigation.

Finally, the 'reverse immunology' approach is a useful method to identify TA A s. It makes use of computer-assisted identification of peptides within the sequence of candidate antigens which fulfill the consensus criteria for binding to an $\mathrm{M} \mathrm{H} \mathrm{C} \mathrm{class}$ I molecule. The peptides are synthesized and tested for their ability to stabilize M HC class I molecules on the cell surface. Subsequently, the frequency of $\mathrm{T}$ cells in patient blood, which react with a given peptide epitope is evaluated to monitor the in vivo relevance of a given antigen. A Iso the sequence determination of peptides which can be eluted from class I molecules of tumor cells and are recognized by tumor-specific CTLS has resulted in the discovery of novel TA A S.

\section{Defined Human Tumor-Associated Antigens and Their Potential for Vaccination Approaches}

A s can be seen in table 1 , a broad spectrum of TA A s has been identified [9]. Theoretically, TA A s that have arisen as a result of somatic mutations in normal gene products represent potent antigens since they are unlikely to have triggered tolerance. H owever, identification and isolation of TA A s from individual patients are clinically not practical and currently not an option. Viral antigens would also make excellent TA A s but are applicable only to a very limited number of malignancies with high prevalence of viral infection, such as cervix carcinoma which is associated in over $90 \%$ of cases with infection by human papilloma virus. A promising target for immunotherapy are TA A s that correspond to normal gene products shared among many 


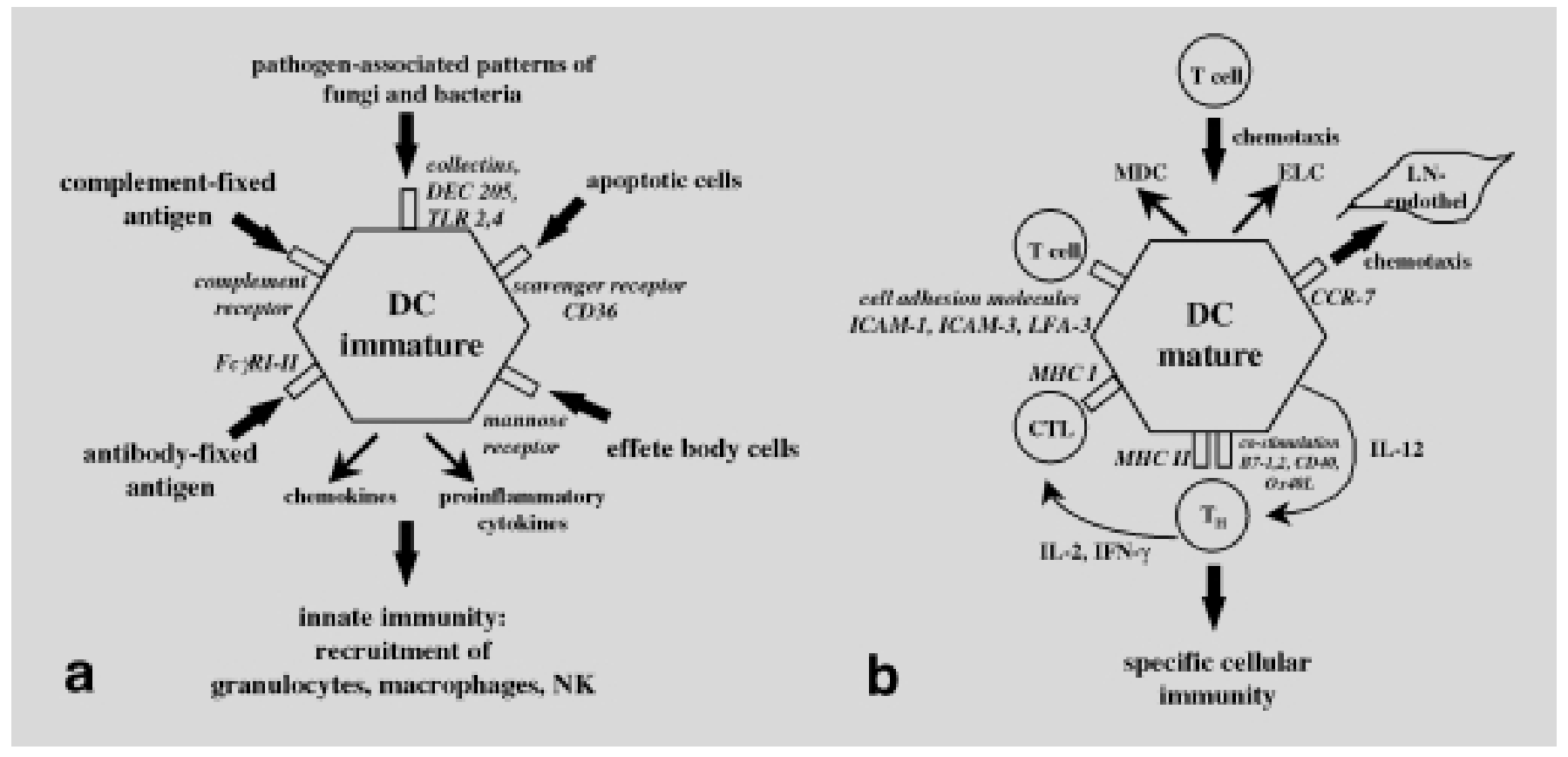

Fig 3. K ey molecules expressed on immature and mature DCs. a I mmature DCs are capable of actively taking up antigens by phagocytosis or receptormediated endocytosis. Subsequently, production of chemokines and proinflammatory cytokines leads to priming of an innate immune response. $\mathbf{b} U$ pon maturation, D Cs downregulate molecules involved in uptake of antigens. In turn, molecules involved in DC-T-cell interaction and in antigen presentation are upregulated. U Itimately, D Cs prime a specific immune response by activating the cellular arm of the specific immune system. The properties of molecules expressed on D Cs are outlined in the section 'D endritic Cells'.

patients. The cancer testis antigens MAGE, GAGE, BAGE, RAGE, SSX, and LAGE-1/NY-ESO-1 are silent in most normal adult tissues but are expressed in cancers of various histological origin. Since the expression of these genes has been observed in many different tumors, the antigens they encode are of enormous practical value for cancer immunotherapy. The only normal tissues that have been found to express these genes are testes and, in some instances, placenta, two tissues regarded as immunologically privileged due to lack of MHC class I expression.

A different group of promising antigens consists of proteins that correspond to normal tissue-specific gene products. Such antigens have been found in melanoma patients and include M A RT-1/M elan A, gp100, and tyrosinase. Expression of these gene products is limited to melanomas as well as melanocytes and pigment-producing cells in the retina. Prostate-specific proteins like prostate-specific antigen (PSA) prostate-specific membrane antigen (PSM A ), and prostatic acidic phosphatase (PA P) (table 1) have also been employed as vaccines against hormone-refractory prostate carcinoma as their expression is frequently conserved in malignant prostatic tissue. Furthermore, overexpression or derepression of $\alpha$-fetoprotein has been demonstrated in a majority of hepatocellular carcinomas, and carcinoembryonic antigen (CEA) and a mucin (M U C-1) are expressed by several epithelial malignancies (table 1). A dditional highly promising candidates for immunotherapeutic strategies are idiotypic determinants of clonal Ig found in B-cell lymphomas.

\section{Antigen-Loaded Autologous DCs as Cellular Vaccines}

While there has been considerable progress in identification of tumor antigens, the traditional methods for delivering antigens seem insufficient for immunotherapy of cancer. Conventional vaccines which are composed of inactivated pathogens or their components aim to stimulate antibody and, to varying degrees, $T_{h}$-cell responses. However, in order to eradicate cancer cells, potent CTL responses are needed. Experiments in murine tumor models have shown that plain peptide vaccination often leads to poor activation or even tolerization of $T$ cells [10], whereas the application of autologous D Cs charged with the same peptides resulted in vigourous CTL activation and the elimination of tumors. This indicates that antigencharged DCs when used as a cellular vaccine can induce stronger cytotoxic responses than conventional vaccines. In clinical trials, synthetic M HC class I-restricted peptides have been loaded ex vivo onto class I molecules of DCs along with proteins like the keyhole limpet hemocyanin (KLH) [11], tetanus toxoid, or tuberculin [12] which are very immunogenic and may contain $T_{h}$ epitopes but which are not expressed in the tumor itself. However, an important conclusion from mouse models is that for a potent antitumor response vaccination with both tumor-specific CTL and $T_{h}$ epitopes is required [13]. Hence, it would be helpful if specific M HC class I- and class II-restricted peptides of tumor antigens could be employed. U nfortunately, this approach is hampered by the 
Table $1 \mathrm{D}$ efined human TA A s

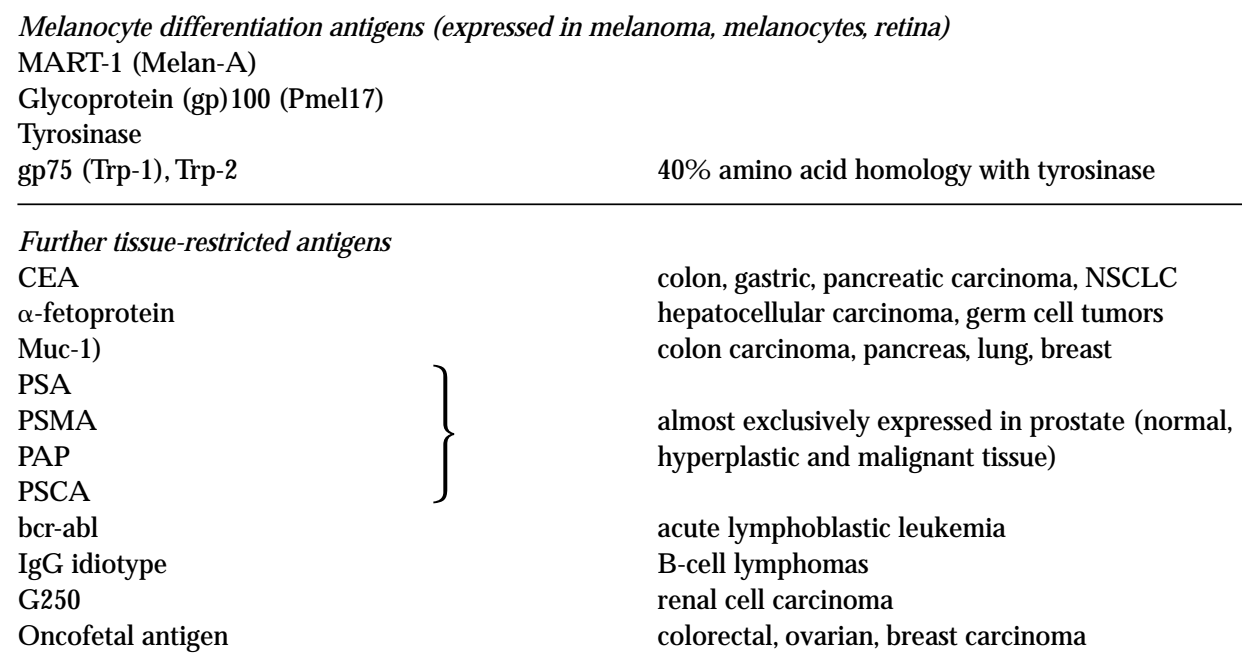

colorectal, ovarian, breast carcinoma

Cancer testis antigens

M A GE -1-13

GAGE-1-8

BAGE

RAGE

PAGE-1,2

NY-E SO-1/LA GE-1

SSX-2 (HOM -M E L 40)

HOM-TES-14

expressed to varying degrees in malignancies of: esophagus, melanoma, ovary, bladder, prostate, lung (M A GE-3 also in in head and neck SCC)

Tumor- and patient-specific mutated gene products CDK-4

$\beta$-Catenin

Caspase-8

HLA -A 2

M um-1

KIA A 0205

p53

ras

$t(X ; 18)$ translocation of synovial sarcoma glioma and breast cancer

Viral origin

HPV-16E 7

HERV-K 10

EBV LM P2B, EBNA -4, gp320

HBV, HCV core proteins

cyclin-dependent kinase, melanoma

melanoma

mutation of stop codon in SCC

renal cell carcinoma

mutation at intron/exon boundary

found in bladder carcinoma line

expressed in many tumors, 'hotspots'

frequent in pancreas carcinoma, colon, 'hotspots'

Widely expressed, but only recognized in tumor tissue SART-1

PRAME

p15

cervical carcinoma (human papilloma virus 16 early gene product 7) env protein of human endogenous retrovirus in RCC non-H odgkin lymphoma, nasopharyngeal carcinoma hepatoma lung, esophagus

NK inhibitory receptor, melanoma melanoma

M uc-1 = M ucin 1; M um = mutated in melanoma; PA P = prostatic acid phosphatase; PR A M E = preferentially expressed antigen of melanoma; PSA = prostate-specific antigen; PSCA = prostate stem cell antigen; $\mathrm{PSMA}=$ prostate-specific membrane antigen; SA RT = SCC antigen recognized by T cells; SCC = squamous cell carcinoma; TR P = tyrosinase-related proteins

diversity of $\mathrm{MHC}$ class I and II alleles of individual patients and by the severe lack of defined MHC class II-restricted peptide epitopes.

A way out of this dilemma would be to charge DCs with recombinant tumor antigens, assuming that they contain epitopes for presentation on both MHC class I and II molecules. Since DCs are able to process endocytosed proteins for presentation on class I and class II molecules, external loading of DCs with recombinant proteins seems useful. Several methods all of which target receptor-mediated endocytosis or phagocytosis are currently being developed. These include the glycosylation of recombinant proteins for uptake by DC lectin receptors or the administration of Ig/antigen immune complexes for uptake via $\mathrm{F} c y$ receptors. Interestingly, DCs can process external proteins much more efficiently for presentation on class I molecules when they are offered in particulate form of a defined size of 1-10 $\mu \mathrm{M}$ [14]. Therefore, the loading of DCs with proteins packaged in biodegradable poly(lactide- 
Table 2. D C -based vaccination trials

\begin{tabular}{|c|c|c|}
\hline Vaccine formulation & Clinical response & R eferences \\
\hline \multicolumn{3}{|l|}{ M alignant melanoma } \\
\hline M A GE-1 peptide + immature D Cs i.v. & 3 patients, no response & 17 \\
\hline M A RT-1, tyrosinase, gp100 peptide + immature D Cs i.v. & 16 patients, 2 CR , 2 PR , 2 M R & 18 \\
\hline Tyrosinase, M A RT-1, gp100, M A GE -1 and 3 peptide mix, immature D Cs intranodally + KLH & 16 patients, 2 CR, 3 PR , 1 M R & 11 \\
\hline M A GE -3 peptide mature D Cs intradermally + tetanus toxoid/tuberculin & 11 patients, 6 PR & 12 \\
\hline \multicolumn{3}{|l|}{ Renal cell carcinoma } \\
\hline Tumor lysate + mature DCs + K LH & 7 patients, 1 PR , 5 SD & 23,24 \\
\hline DC tumor cell fusion, lethally irradiated & 17 patients, 4 CR , 2 PR , 2 SD & 25 \\
\hline \multicolumn{3}{|l|}{ Pancreas carcinoma } \\
\hline Peptide mutant p21ras + PBM C i.v. & 5 patients, no clinical response & 22 \\
\hline \multicolumn{3}{|l|}{ Non-H odgkin lymphoma } \\
\hline I mmature D Cs pulsed with Id +KLH i.v. & 10 patients, 3 CR/PR , 6 SD & 27 \\
\hline \multicolumn{3}{|l|}{ Prostate carcinoma } \\
\hline 2 peptides derived from PSM A, immature DCs i.v. & 33 patients, 2 CR , 6 PR , 1 SD & 19 \\
\hline \multicolumn{3}{|l|}{ Colorectal, breast, lung carcinoma } \\
\hline I mmature DCs pulsed with CEA-R NA & 26 patients, 1 CR/PR , 2 M R , 4 SD & 20,21 \\
\hline CEA -derived peptides i.v. & 19 patients, 1 M R, 1 SD & 20,21 \\
\hline
\end{tabular}

$C R=$ Complete response; $P R=$ partial response; $M R=$ mixed response; $S D=$ stable disease.

co-glycolide) (PLG) microparticles is currently under investigation [15, 16]. A Iternatively, D Cs may be efficiently loaded with exosomes from DCs or apoptotic bodies derived from tumor cells.

\section{Clinical Trials Employing DC-Based Vaccination}

Currently, DC-based immunotherapeutic approaches have just reached the stage of human clinical trial. Initial results several of which appear very promising have recently been reported (table 2). DC immunotherapy is most advanced in melanoma due to the extensive body of knowledge about melanoma-associated antigens. Clinical trials with stage IV patients (life expectancy of about 6 months) have been performed in E rlangen (G ermany) [12], Zürich (Switzerland) [11], Farmington [17] and L os A ngeles (U SA) [18]. These trials (except the M A GE -1 vaccination [17]) show similar clinical outcomes with response rates varying from 20 to $40 \%$ even though different antigens and routes of administration (intravenous (i.v.), intradermal as well as intranodal) had been utilized (table 2). A lso tumors which so far were considered much less immunogenic than melanoma as for instance hormone-refractory prostate carcinoma yielded clinical responses (table 2) [19]. Some encouraging results have been obtained with vaccination strategies based on CEA for colorectal, breast, and lung carcinoma [20, 21], mutated ras peptides for pancreas carcinoma [22], and tumor lysate for renal cell carcinoma [23, 24]. On the other hand, very encouraging clinical results were achieved in the immunotherapy of renal cell carcinoma, utilizing a different approach [25]. A utologous tumor cells have been fused with allogeneic DCs in an electrical field, lethally irradiated, and re-injected into patients, leading to striking clinical responses.
It is premature at this stage to attempt conclusions regarding which DC-based approach to immunotherapy would be the most promising since our current level of understanding concerning pivotal issues of cancer vaccination is too preliminary. $K$ ey questions still to be resolved include the number of $D C s$ used for vaccination which varies by 2 logs between different trials and the frequency and schedule of DC administration. We do not know for instance how long the treatment will have to be continued and in what intervals. It is also a matter of current debate which differentiation state of D C s is best and what route of administration should be used. The latter issue was addressed by a recent study which analyzed the biodistribution of in vitro-generated, antigen-loaded human D Cs labeled with Indium-111 oxyquinoline after i.v., subcutaneous (s.c.) and intradermal injection [20]. While the D C s injected i. v. localized in lungs and then redistributed to liver, spleen and bone marrow, they were not detected in lymph nodes or tumors. The same applies to D C s injected s.c. Only intradermal injection led to a small percentage of DCs that migrated rapidly to the regional lymph nodes. It should be emphasized that the various parameters of DC-based vaccination in human cannot be inferred from mouse experiments, and it will be a daunting but unavoidable task to determine these important parameters in separate clinical trials in the human setting.

Finally, the development of standard criteria (besides clinical response) for evaluating and comparing the efficacy of vaccine formulations is of great importance. E specially the quantitative assessment of specific CTL responses is difficult because the frequency of specific CT L s in the blood is too low to quantify them in functional assays without prior restimulation of CTLs with antigen-loaded A PCs in vitro. This amplification step, however, may distort the picture which is found in the patient. 


\section{The Issue of Autoimmunity}

It has recently been shown in a murine model that $D C$ vaccination may induce autoimmune destruction of islet cells of the pancreas expressing the target antigen [26]. During the DCbased vaccination of melanoma patients with melanocyte antigens, tumor regression was occasionally associated with destruction of melanocytes, resulting in depigmentation of the skin (vitiligo). R emarkably, signs of autoimmunity leading to dysfunction of other organs have not been reported in these cases. O nly occasionally modest and transient elevations of antinuclear or anti-TSH (thyroid-stimulating hormone) receptor antibodies were observed after extensive vaccinations [11]. In general, vaccination with autologous DCs was very well tolerated and did not show side effects, except for local reactions (erythema, induration, pruritus) and elevation of body temperature.

Even in clinical trials in which DCs have been loaded with tumor lysates [11, 23] or total R NA of tumors, no significant signs of autoimmunity have been reported. O ne possible explanation for the lack of autoimmunity is that the stimulation of CTL responses is simply too weak to induce autoaggression. A Iternatively, the mechanisms of inducing peripheral tolerance to antigens which are contained in tumor cells as well as other tissues may prevent activation of autoreactive $T$ cells. A t present, this issue is unresolved, and vaccination with complex and undefined protein mixtures will continue as long as clinical evidence for severe autoimmune destruction is lacking. H owever, if we succeed to improve the potency of antitumor responses by developing better vaccine formulations, autoimmunity may become an issue. In this case, it would be important to have defined tumor-specific antigens which are presently unknown for the majority of neoplastic diseases. These antigens should ideally be expressed in a majority of tumors but should be absent from tissues which are essential for survival. It therefore seems justified to continue the search for tumor antigens expressed by different types of malignancies.

\section{Conclusion}

DC-based tumor vaccination is a promising novel treatment modality that can augment standard treatment options for malignancies. In DC-based vaccination trials complete and partial responses in patients with malignant melanoma, renal cell carcinoma, and hormone-refractory prostate cancer have been obtained at frequencies which have not been observed previously with established modes of treatment. A Ithough the clinical data argue that $D C$-based vaccination may be effective, a final proof of principle will require larger trials with randomized patient accrual to determine the statistical significance of the reported findings. The outcome of such trials will tell how effective DC-based vaccination is compared to radio- or chemotherapy and whether it will become a routine treatment in the combat against cancer.

\section{Acknowledgements}

We thank Frank Nestle and L uis Filgueira for the contribution of figure 2 and acknowledge Frank Nestle and Silke Gillessen for critical reading of the manuscript. Our work is supported by the Swiss Cancer League, Cancer L eague St. G allen-A ppenzell, Foundation Propter H omines, O SK K, Dietschweiler Foundation, Spühl Foundation, Cancer Research Insitute, CaP CURE Foundation, and A straZ eneca A G.

\section{References}

1 Cella $M$, Scheidegger D, Palmer-L ehmann $K$, L ane $P$, $L$ anzavecchia A, A lber G : Ligation of CD 40 on dendritic cells triggers production of high levels of interleukin-12 and enhances $T$ cell stimulatory capacity: T-T help via A PC activation. J Exp Med 1996;184: 747-752.

2Thompson CB, A llison JP: The emerging role of CTLA -4 as an immune attenuator. Immunity 1997;7: 445-450.

3 B anchereau J, Steinman R M : D endritic cells and the control of immunity. N ature 1998;392:245-252.

4 R omani N, Gruner S, Brang D, K ampgen E, Lenz A Trockenbacher B, Konwalinka G, Fritsch PO, Steinman R M , Schuler G : Proliferating dendritic cell progenitors in human blood.J Exp M ed 1994;180:83-93.

5 Sallusto F, L anzavecchia A : E fficient presentation of soluble antigen by cultured human dendritic cells is maintained by granulocyte/macrophage colonystimulating factor plus interleukin 4 and downregulated by tumor necrosis factor alpha.J Exp M ed 1994; 179:1109-1118.

6Jonuleit H, Kuhn U, Muller G, Steinbrinck K Paragnik L, Schmitt E, Knop J, Enk A H : Pro-inflammatory cytokines and prostaglandins induce maturation of potent immunostimulatory dendritic cells under fetal calf serum-free conditions. E ur J I mmunol 1997; 27:3135-3142.
7 van der $B$ ruggen $P$, Traversari $C$, Chomez $P$, L urquin $C, D$ ePlaen $E$, Van den Eynde B, K nuth A, B oon T: A gene encoding an antigen recognized by cytolytic $T$ lymphocytes on a human melanoma. Science 1991;254:1643-1647.

8 Tureci O, Sahin U, Pfreundschuh M : Serological analysis of human tumor antigens: M olecular definition and implications. M ol Med Today 1997;3:342-349.

$9 \mathrm{G}$ ilboa $\mathrm{E}$ : The makings of a tumor rejection antigen. Immunity 1999:11:263-270.

$10 \mathrm{Diehl} L$, den Boer AT, Schoenberger SP van der Voort EI, Schumacher TN, M elief CJ, Offringa R, Toes RE: CD 40 activation in vivo overcomes peptide-induced peripheral cytotoxic T-lymphocyte tolerance and augments anti-tumor vaccine efficacy. $N$ at $M$ ed 1999:5:774-779.

11 Nestle FO, A lijagic S, G illiet M, Sun Y, G rabbe S, D ummer R, Burg G, Schadendorf $D:$ Vaccination of melanoma patients with peptide- or tumor lysatepulsed dendritic cells. N at M ed 1998;4:328-332.

12 Thurner $B, H$ aendle I, Roder C, Dieckmann $D$, Keikavoussi $P$, Jonuleit $H$, Bender $A$, M aczek $C$ Schreiner $D$, von den Driesch $P$, B rocker $E B$, Steinman RM, Enk A, Kampgen E, Schuler G: Vaccination with mage-3A 1 peptide-pulsed mature monocyte-derived dendritic cells expands specific cytotoxic $T$ cells and induces regression of some metastases in advanced stage IV melanoma. J Exp M ed 1999;190:1669-1678.
13 O ssendorp F, M engede $E$, C amps M , Filius R, M elief CJM : Specific T helper cell requirement for optimal induction of cytotoxic $T$ lymphocytes against major histocompatibility complex class II negative tumors. J Exp M ed 1998;187:693-702.

14 Shen Z, R eznikoff G, D ranoff G, R ock K L : Cloned dendritic cells can present exogenous antigens on both M HC class I and class II molecules. J Immunol 1997;158:2723-2730.

15 R aychaudhuri S, Rock KL: Fully mobilizing host defense: Building better vaccines. Nat Biotechnol 1998;16:1025-1031.

16 M en $Y$, A udran R, Thomasin C, E berl G, D emotz $S$, Merkle HP, Gander B, Corradin G: MHC class I- and class II-restricted processing and presentation of microencapsulated antigens. Vaccine 1999;17: 1047-1056.

17 M ukherji B, Chakraborty NG, Yamasaki S, O kino T, Yamase $H$, Sporn JR, Kurtzman SK, Ergin MT, O zols J, M eehan J, M auri F: Induction of antigenspecific cytolytic $T$ cells in situ in human melanoma by immunization with synthetic peptide-pulsed autologous antigen presenting cells. Proc $\mathrm{N}$ atl $\mathrm{A}$ cad Sci U SA 1995;92:8078-8082.

18 Salgaller ML, Thurnher M, B artsch G, B oynton A L, M urphy G P: R eport from the International U nion A gainst $C$ ancer (UICC) Tumor B iology Committee: UICC workshop on the use of dendritic cells in cancer clinical trials. Cancer 1999;86:2674-2683. 
19 T joa BA , Simmons SJ, E Igamal A , R ogers M , R agde H , K enny G M , Troychak M J, Boynton A L, Murphy GP: Follow-up evaluation of a phase II prostate cancer vaccine trial. Prostate 1999;40:125-129.

20 M orse M A , D eng Y, Coleman D, H ull S, K itrell-Fisher E, N air S, Schlom J, R yback $M E$, Lyerly $H K$ : A phase I study of active immunotherapy with carcinoembryonic antigen peptide (CA P-1)-pulsed, autologous human cultured dendritic cells in patients with metastatic malignancies expressing carcinoembryonic antigen. Clin Cancer R es 1999;5:1331-1338.

21 Nair SK, Hull S, Coleman D, G ilboa E, Lyerly HK, M orse M A : Induction of carcinoembryonic antigen (CEA)-specific cytotoxic T-lymphocyte responses in vitro using autologous dendritic cells loaded with CEA peptide or CEA RNA in patients with metastatic malignancies expressing CEA. Int J Cancer 1999;82: 121-124.

22 G jertsen MK, Bakka A, B reivik J, Saeterdal I, Gedde-Dahl T III, Stokke KT, Solheim BG, E gge TS, Soreide 0 , Thorsby E, G audernack G : Ex vivo ras peptide vaccination in patients with advanced pancreatic cancer: R esults of a phase I/II study. Int J Cancer 1996;65:450-453.

$23 \mathrm{H}$ oltl L, R ieser C, Papesh C, R amoner R, B artsch G, Thurnher M : CD 83+ blood dendritic cells as a vaccine for immunotherapy of metastatic renal-cell cancer (letter). L ancet 1998;352:1358

$24 \mathrm{H}$ oltl L, R ieser C, Papesh C, R amoner R, H erold M , K locker H , R admayr C, Stenzl A, Bartsch $G$, Thurnher $M$ : Cellular and humoral immune responses in patients with metastatic renal cell carcinoma after vaccination with antigen pulsed dendritic cells. J U rol 1999;161:777-782.

25 Kugler A, Stuhler G, Walden P, Zöller G, Zobywalski A, B rossart P, Trefzer U, U llrich S, M üller CA, B ecker V, G ross A J, H emmerlein B, K anz L, M üller GA $R$ ingert $\mathrm{RH}$ : R egression of human metastatic renal cell carcinima after vaccination with tumor cell-dendritic cell hybrids. $\mathrm{N}$ at M ed 2000;6:332-336.

$26 \mathrm{~L}$ udewig B, O dermatt B, L andmann S, H engartner H , Z inkernagel R M : D endritic cells induce autoimmune diabetes and maintain disease via de novo formation of local lymphoid tissue. J Exp M ed 1998;188:1493-1501.

27 H su FJ, B enike C, Fagnoni F, L ilesTM , Czerwinski D, Taidi B, Engleman E G, L evy $R: V a c c i n a t i o n$ of patients with $B$-cell lymphoma using autologous antigen-pulsed dendritic cells. Nat M ed 1996;2:52-58.

28 N estle FO, Z heng X, Thompson CB, Turka LA , Nickoloff BJ : Characterization of dermal dendritic cells obtained from normal human skin reveals phenotypic and functionally distinctive subsets. J I mmunol 1993;151:6535-6545.

D endritic Cell-B ased Tumor Vaccination 